\title{
Prevalence and molecular characteristics of 16s rRNA methylase gene rmtB in amikacin resistant Escherichia coli isolated from South Korea
}

\author{
Kuastros Mekonnen Belaynehe ${ }^{1,4}$, Ho Geun Won ${ }^{1,2}$, In Joong Yoon ${ }^{2}$, Han Sang Yoo ${ }^{1,3, *}$ \\ ${ }^{I}$ Department of Infectious Diseases, College of Veterinary Medicine, Seoul National University, Seoul 08826, Korea \\ ${ }^{2}$ Chung Ang Vaccine Laboratory, Daejeon 34055, Korea \\ ${ }^{3}$ Bio-MAX/N-Bio, Seoul National University, Seoul 08826, Korea \\ ${ }^{4}$ National Animal Health Diagnostic and Investigation Center, Sebeta 04, Ethiopia
}

\begin{abstract}
The production of $r m t B$-encoded 16S rRNA methylases has emerged as a novel mechanism promoting high-level resistance toward aminoglycosides in Gram-negative bacteria. Between 2015 and 2017, 636 distinct commensal Escherichia (E.) coli isolates were collected from different farms in South Korea to determine the prevalence and molecular characteristics of $r m t B$. The positive rates of $r m t B$ between all the isolates and amikacin-resistant isolates were 1.1 and $100 \%$, respectively. High-level aminoglycoside resistance could be transferred by conjugation from $r m t B$-positive donors to higher amikacin-resistance efficacies. This is the first report of $16 \mathrm{~S}$ rRNA methylase-encoding genes in $E$. coli isolated from food-producing animals in Korea.
\end{abstract}

Keywords: Escherichia coli, 16S RMTase gene, amikacin resistance, transferability

*Corresponding author

Han Sang Yoo

Department of Infectious Diseases, College of Veterinary Medicine, Seoul National University, Seoul 08826, Korea.

Tel: $+82-2-880-1263$

Fax: +82-2-874-2738

E-mail: yoohs@snu.ac.kr

ORCID:

Kuastros Mekonnen Belaynehe https://orcid.org/0000-0002-8508-0809 Ho Geun Won https://orcid.org/0000-0003-4568-4429 In Joong Yoon https://orcid.org/0000-0002-8761-4296 Han Sang Yoo https://orcid.org/0000-0003-0548-0835

Conflict of Interest

The authors declare no conflicts of interest.

Received: August 19, 2019

Accepted: September 11, 2019
The mechanism of the clinically significant aminoglycosides has long been known to be associated with their ability to bind to the bacterial $30 \mathrm{~S}$ ribosomal subunit and interfere with bacterial protein translation [1]. Serious infections caused by Gram-negative bacteria can often be effectively treated with a combination of aminoglycoside- $\beta$-lactam agents [2]. However, the clinical significance and effectiveness of aminoglycosides have been challenged by different bacterial resistance mechanisms. Among the globally disseminated aminoglycoside resistance mechanisms, acquired 16S ribosomal RNA methyltransferases (16S RMTases) in Gram-negative bacteria are the most worrisome due to their ability to compromise the activity of all aminoglycosides [3]. 16S RMTases confer resistance to aminoglycosides by methylating a nucleotide in the aminoglycoside attachment region located in the A-site of the 16S rRNA using S-adenyosyl-L-methionine [2].

The aminoglycoside binding site of the specific nucleotide residues, either the N-7 position of nucleotide $\mathrm{G} 1405$ or the $\mathrm{N}-1$ position of nucleotide A1408, in 16S rRNA can be enzymatically modified by various 16S rRNA methyltransferases [4,5]. There are ten acquired N7-G1405 16S RMTaseencoding genes ( $a r m A, r m t A, r m t B, r m t C, r m t D, r m t D 2, r m t E, r m t F, r m t G$, and $r m t H)$, although only one acquired N1-A1408 16S RMTase gene (npmA) exclusively confers resistance to aminoglycosides. The first encoded $16 \mathrm{~S}$ RMTase was discovered in Japan in 1997 on a plasmid harboring $r m t A$ in an AGA-resistant Pseudomonas aeruginosa strain [6]. Later, in the early 2000s, significant progress in the field of genetic analytical techniques led to discovery of another member of the $16 \mathrm{~S}$ rRNA methylase gene family, armA, in Klebsiella pneumoniae isolated from a hospitalized patient in France [7]. Recently, O'Hara et al. [8] identified $r m t H$ from a clinical K. pneumoniae strain in a wounded male USA solder returning from the Iraq war.

Despite exhibiting a low clinical prevalence, the clinical significance of $16 \mathrm{~S}$ RMTases is increasing globally, posing considerable potential health risks due to $16 \mathrm{~S}$ RMTases being able to confer resistance to many clinically important aminoglycosides, including amikacin. The predominant 16S RMTases are currently encoded by $r m t B$ and $a r m A$, which have spread worldwide to resistant 
bacterial strains isolated from humans and livestock $[9,10]$. In South Korea, 16S RMTase genes has been reported from human clinical E. coli isolates, with the most commonly encountered 16S RMTase genes responsible for aminoglycoside-resistance being $\operatorname{arm} A$ and $r m t B$ [11].

However, the prevalence of high-level aminoglycoside resistance mediated by $16 \mathrm{~S}$ rRNA methylases among $E$. coli strains isolated from food-producing animals has not been investigated. In this study, we describe the identification of $r m t B$ in a commensal $E$. coli strain recovered from healthy animals. Thus, the aim of this study was to investigate the prevalence of $r m t B$ among $E$. coli isolates collected in South Korea and to gain insights into the molecular characterization of these $r m t B$-positive strains.

We screened 636 commensal $E$. coli isolates recovered from fecal samples obtained from clinically healthy animals (341 from cattle, 265 from swine, and 30 from chickens) during a nationwide surveillance study on antimicrobial susceptibility conducted between 2014 and 2017. Fecal samples were freshly collected from cattle, swine, and chickens, and E. coli isolates were obtained by culturing on MacConkey and Eosin methylene blue agar.

MIC testing was conducted according to the recommendations of the Clinical Laboratory Standards Institute (CLSI) (2015), and the resulting MIC values were interpreted using CLSI standards. An inoculum of $10^{5} \mathrm{CFU} / \mathrm{mL}$ was incubated in Mueller-Hinton broth (MHB) in the presence of two-fold serial dilutions of antimicrobials, with the MIC defined as the lowest concentration of antibiotic that completely inhibited visible growth. The following antimicrobial agents were tested in the described range of concentrations $(\mathrm{mg} / \mathrm{L})$ : amikacin (0.25-512), streptomycin (0.125-128), gentamicin (0.125-128), kanamycin(0.25-256), neomycin (0.125-256), tobramycin (0.125-256), tetracycline (0.25-512), ampicillin (0.125-256), minocycline (0.25-512), and cephalothin (0.125-128).

PCR amplification to investigate the 16S RMTase-encoding genes $(r m t A, r m t B, r m t C, r m t D, r m t E$, armA, and $n p m A)$ along with other resistance mechanisms was carried on strains displaying phenotypic resistance for amikacin by employing primer pairs reported in previous studies $[4,12,13]$.

Conjugation experiments were performed to determine the transferability of $16 \mathrm{~S}$ rRNA methylase genes between the donor and recipient strains using the broth mating technique. The transconjugants were selected for and confirmed by PCR. The MICs for recipient, transconjugant, and donor strains were determined using the broth microdilution method with procedures and interpretation guidelines of the CLSI [14].

High-level amikacin resistance (MIC $\geq 512 \mu \mathrm{g} / \mathrm{mL}$ ) was observed in $7(1.1 \%)$ of the 636 assayed $E$. coli isolates. Of the investigated $16 \mathrm{~S}$ rRNA methylase genes, only $r m t B$ was detected in all 7 isolates, whereas all the isolates tested negative for the armA, rmtA, rmtC, rmtD, rmtE, and $n p m A$ genes (Table 1). The conjugation assay results confirmed the successful transfer of amikacin resistance to 3 of the $7 \mathrm{rmtB}$-positive isolates by conjugation to the azide-resistant $E$. coli strain J53. The presence of the $r m t B$ gene was confirmed by PCR in 3 of the transconjugants, which showed the same resistance profiles for amikacin (MIC $\geq 512 \mu \mathrm{g} / \mathrm{mL}$ ) as the donor isolates (Table 2). The three transconjugants were selected with amikacin at a conjugation frequency of 1.73 $\times 10^{-2}$ to $5.1 \times 10^{-3}$ (number of transconjugants divided by the number of donor cells) (Table 3 ).

In addition to impermeability and multidrug-active efflux systems, the primary mechanism of aminoglycoside resistance involves modification of the target region by enzymes that are collectively known as aminoglycoside modifying enzymes (AMEs) [3]. We previously reported that commensal $E$. coli isolates from food-producing animals in Korea have a tremendous ability to harbor and transfer AME genes [15]. More recently, 16S rRNA methylases have become an important public health threat due to their ability to confer high-level and broad-spectrum resistance to most clinically relevant aminoglycosides [9]. To the best of our knowledge, we here report for the first time a molecular epidemiological based investigation of $16 \mathrm{~S}$ rRNAmethylase gene, $r m t B$, carrying $E$. coli strains in Korea. All $7 \mathrm{rmtB}$-carrying isolates

Table 1. MICs, phylogroups and antimicrobial resistance gene profiles for amikacin-resistant Escherichia coli isolates of animal origin from South Korea collected between 2015 and 2017

\begin{tabular}{|c|c|c|c|c|c|c|}
\hline Isolates & $\begin{array}{l}\text { Year of } \\
\text { isolation }\end{array}$ & $\begin{array}{l}\text { Phylogenetic } \\
\text { group }\end{array}$ & Origin & Amikacin MIC & $\begin{array}{c}\text { 16S rRNA } \\
\text { methyltransferase gene }\end{array}$ & Other resistance genes \\
\hline $16 \mathrm{~S}-242$ & 2016 & $\mathrm{D}$ & Pig & $\geq 512 \mu \mathrm{g} / \mathrm{mL}$ & $r m t B$ & $T E M, a p h 3^{\prime}-1 a$ \\
\hline DCA4324 & 2017 & $\mathrm{D}$ & Pig & $\geq 512 \mu \mathrm{g} / \mathrm{mL}$ & $r m t B$ & $\begin{array}{l}\text { tetA, sul1, sul2, TEM, floR, } \\
\text { Str } A B\end{array}$ \\
\hline DCA4358 & 2017 & A & Pig & $\geq 512 \mu \mathrm{g} / \mathrm{mL}$ & $r m t B$ & $\begin{array}{l}\text { tetA, tetB, sull, sul2, TEM, } \\
\text { cat, Str } A B \text {, aadB, aph3'-la }\end{array}$ \\
\hline DCA4403 & 2017 & A & Pig & $\geq 512 \mu \mathrm{g} / \mathrm{mL}$ & $r m t B$ & tetA, sul2, TEM, aph3'-1a \\
\hline EC504 & 2015 & A & Pig & $\geq 512 \mu \mathrm{g} / \mathrm{mL}$ & $r m t B$ & $\begin{array}{l}\text { tetB, sul1, sul2, sul3, TEM, } \\
\text { cat, StrAB, aph3'-1a }\end{array}$ \\
\hline EC716 & 2015 & A & Pig & $\geq 512 \mu \mathrm{g} / \mathrm{mL}$ & $r m t B$ & $\begin{array}{l}\text { tetA, sul1, sul2, sul3, TEM, } \\
\text { floR, StrAB, aph3'-1a }\end{array}$ \\
\hline EC766 & 2015 & A & Pig & $\geq 512 \mu \mathrm{g} / \mathrm{mL}$ & $r m t B$ & $\begin{array}{l}\text { tetB, sull, sul2, TEM, cat, } \\
\text { Str } A B, \text { aadB, aph3'-la }\end{array}$ \\
\hline
\end{tabular}


Table 2. Antimicrobial resistance profile of $r m t B$-harboring Escherichia coli transconjugants

\begin{tabular}{lccccccc}
\hline \hline \multirow{2}{*}{ Transconjugants } & 16S rRNA & \multicolumn{5}{c}{ MIC value $(\mu \mathrm{g} / \mathrm{mL})$} \\
\cline { 3 - 7 } & methylase gene & AMK & CAZ/CLA & CAZ & CTX & CTX/CLA & MEM \\
\hline TC504 & $r m t B$ & $\geq 512$ & 0.5 & 0.5 & 0.5 & 0.25 & 0.06 \\
TC716 & $r m t B$ & $\geq 512$ & 0.5 & 0.25 & 1 & 1 & 0.06 \\
TC358 & $r m t B$ & $\geq 512$ & 0.25 & 0.5 & 1 & 1 & 0.06 \\
ATCC29212 & - & 2 & 0.25 & 0.25 & 1 & 0.5 & 0.03 \\
\hline
\end{tabular}

AMK, amikacin; CAZ/CLA, ceftazidime-clavulanic acid; CTX/CLA, cefotaxime-clavulanic acid; MEM, meropenem; ATCC, American Type Culture Collection.

Table 3. Transferability and conjugation frequencies of $r m t B$-harboring Escherichia coli isolates from food-producing animals in South Korea

\begin{tabular}{|c|c|c|c|c|}
\hline Isolates & Number of $\mathrm{CFU} / \mu \mathrm{L}$ of isolates & Transferability & $\begin{array}{c}\text { Number of CFU/ } \mu \mathrm{L} \text { of } \\
\text { transconjugants }\end{array}$ & Conjugation efficiency \\
\hline $16 \mathrm{~S}-242$ & $2.54 \times 10^{6} / \mu \mathrm{L}$ & - & - & - \\
\hline DCA4324 & $2.48 \times 10^{6} / \mu \mathrm{L}$ & - & - & - \\
\hline DCA4358 & $2.54 \times 10^{6} / \mu \mathrm{L}$ & + & $4.4 \times 10^{4} / \mu \mathrm{L}$ & $1.73 \times 10^{-2}$ \\
\hline DCA4403 & $2.5 \times 10^{5} / \mu \mathrm{L}$ & - & - & - \\
\hline EC504 & $2.66 \times 10^{6} / \mu \mathrm{L}$ & + & $1.92 \times 10^{5} / \mu \mathrm{L}$ & $7.2 \times 10^{-2}$ \\
\hline EC716 & $3.35 \times 10^{6} / \mu \mathrm{L}$ & + & $1.7 \times 10^{4} / \mu \mathrm{L}$ & $5.1 \times 10^{-3}$ \\
\hline EC766 & $2.78 \times 10^{6} / \mu \mathrm{L}$ & - & - & - \\
\hline E. coli $\mathrm{J} 53$ & $1.28 \times 10^{6} / \mu \mathrm{L}$ & Recipient & Recipient & \\
\hline
\end{tabular}

were highly resistant to amikacin (MIC value of $\geq 512 \mu \mathrm{g}$ / $\mathrm{mL}$ ), a resistance phenotype consistent with production of a 16S RMTase.

In this study, the overall prevalence $(1.1 \%)$ of $16 \mathrm{~S}$ rRNA methylase genes in E. coli isolates was similar to that previously reported in a Taiwanese study $(0.4 \%)$ [16], but lower than was observed in a study from China (5.4\%) [17]. Generally, a low relatively low prevalence of acquired $16 \mathrm{~S}$ RMTases has been reported, with lower prevalence rates of $1 \%$ or less having been reported in different regions of the world [18].

Although we investigated all the known 16S RMTase genes, we only detected the $r m t B$ gene, which is the most prevalent 16S RMTase gene among Enterobacteriaceae isolates [4]. 16S rRNA methylase genes have been linked to other resistance determinants, such as AME genes, tet genes, bla ${ }_{\mathrm{TEM}}$, cat, sul genes, and floR (Table 1). Our data are consistent with those of other studies, indicating that these resistance determinants are co-harbored on a similar plasmid [17]. Amikacin resistance was transferrable from three of seven $r m t B$-positive strains by conjugation. The MICs of amikacin against transconjugants were uniform $(\geq 512 \mu \mathrm{g} / \mathrm{mL})$, suggesting a similar expression of the $r m t B$ gene in the transconjugants. PCR analyses also confirmed the presence of $r m t B$ in three transconjugants. Similarly, a previous study showed that the $r m t B$ gene was readily transferable to a recipient strain since the gene can be both plasmid and chromosomally encoded [19].

In conclusion, the prevalence of $16 \mathrm{~S}$ rRNA methylases, while still low, is increasing and will continue to be reported globally. Plasmid-mediated $16 \mathrm{~S}$ rRNAmethylase $r m t \mathrm{~B}$ gene was detected among commensal $E$. coli isolates from foodproducing animals in South Korea. These results have a strong impact on the treatment options used in both veterinary and human medicine since $16 \mathrm{~S}$ rRNA methylases can hamper the effectiveness of most clinically relevant aminoglycoside antibiotics.

\section{Acknowledgments}

This study was supported by the "the Strategic Initiative for Microbiomes in Agriculture and Food, MAFRA (No. iPET918020-4), the Research Institute of Veterinary Science and the BK21 PLUS program, Seoul National University, Republic of Korea.

\section{References}

1. Fosso MY, Li Y, Garneau-Tsodikova $\mathrm{S}$. New trends in aminoglycosides use. MedChemComm 2014;5:1075-1091.

2. Garneau-Tsodikova S, Labby KJ. Mechanisms of resistance to aminoglycoside antibiotics: overview and perspectives. Med ChemComm 2016;7:11-27.

3. Becker B, Cooper MA. Aminoglycoside antibiotics in the 21st century. ACS Chem Biol 2013;8:105-115.

4. Doi Y, Arakawa Y. 16S ribosomal RNA methylation: emerging resistance mechanism against aminoglycosides. Clin Infect Dis $2007 ; 45: 88-94$

5. Morić I, Savić M, Ilić-Tomić T, Vojnović S, Bajkić S, Vasiljević B. rRNA Methyltransferases and their role in resistance to antibiotics. J Med Biochem 2010;29:165-174. 
6. Yokoyama K, Doi Y, Yamane K, Kurokawa H, Shibata N, Shibayama K, Yagi T, Kato H, Arakawa Y. Acquisition of 16S rRNA methylase gene in Pseudomonas aeruginosa. Lancet 2003;362:1888-1893.

7. Galimand M, Courvalin P, Lambert T. Plasmid-mediated highlevel resistance to aminoglycosides in Enterobacteriaceae due to $16 \mathrm{~S}$ rRNA methylation. Antimicrob Agents Chemother 2003;47:2565-2571.

8. O'Hara JA, McGann P, Snesrud EC, Clifford RJ, Waterman PE, Lesho EP, Doi Y. Novel 16S rRNA methyltransferase $R m t \mathrm{H}$ produced by Klebsiella pneumoniae associated with war-related trauma. Antimicrob Agents Chemother 2013;57: 2413-2416

9. Wachino J, Arakawa Y. Exogenously acquired 16S rRNA methyltransferases found in aminoglycoside-resistant pathogenic Gram-negative bacteria: an update. Drug Resist Updat 2012; 15:133-148

10. Deng YT, Zeng ZL, Tian W, Yang T, Liu JH. Prevalence and characteristics of $r m t \mathrm{~B}$ and qepA in Escherichia coli isolated from diseased animals in China. Front Microbiol 2013;4:198

11. Lee TH, Hwang JH, Lee WK, Shin MK, Woo HR, Chung $\mathrm{KM}$, Lee CS. ArmA and RmtB were the predominant $16 \mathrm{~S}$ RMTase genes responsible for aminoglycoside-resistant isolates in Korea. J Korean Med Sci 2018;33:e262.

12. Davis MA, Baker KN, Orfe LH, Shah DH, Besser TE, Call DR. Discovery of a gene conferring multiple-aminoglycoside resistance in Escherichia coli. Antimicrob Agents Chemother 2010;54:2666-2669.

13. Zhou Y, Yu H, Guo Q, Xu X, Ye X, Wu S, Guo Y, Wang M. Distribution of $16 \mathrm{~S}$ rRNA methylases among different species of Gram-negative bacilli with high-level resistance to aminoglycosides. Eur J Clin Microbiol Infect Dis 2010;29: 1349-1353

14. Clinical Laboratory and Standards Institute (CLSI). Performance standards for antimicrobial susceptibility testing; 25th informational supplement. CLSI M100-S25. Clinical and Laboratory Standards Institute, Wayne, PA: Clinical and Laboratory Standards Institute; 2015.

15. Belaynehe KM, Shin SW, Park HT, Yoo HS. Occurrence of aminoglycoside-modifying enzymes among isolates of Escherichia coli exhibiting high levels of aminoglycoside resistance isolated from Korean cattle farms. FEMS Microbiol Lett 2017;364: fnx129.

16. Yan JJ, Wu JJ, Ko WC, Tsai SH, Chuang CL, Wu HM, Lu YJ, Li JD. Plasmid-mediated 16S rRNA methylases conferring high-level aminoglycoside resistance in Escherichia coli and Klebsiella pneumoniae isolates from two Taiwanese hospitals. J Antimicrob Chemother 2004;54:1007-1012.

17. Yu FY, Yao D, Pan JY, Chen C, Qin ZQ, Parsons C, Yang LH, Li QQ, Zhang XQ, Qu D, Wang LX. High prevalence of plasmid-mediated $16 \mathrm{~S}$ rRNA methylase gene rmtB among Escherichia coli clinical isolates from a Chinese teaching hospital. BMC Infect Dis 2010;10:184.

18. Doi Y, Wachino JI, Arakawa Y. Aminoglycoside resistance: the emergence of acquired 16S ribosomal RNA methyltransferases. Infect Dis Clin North Am 2016;30:523-537.

19. Yu T, He T, Yao H, Zhang JB, Li XN, Zhang RM, Wang GQ. Prevalence of $16 \mathrm{~S}$ rRNA methylase gene $r m t \mathrm{~B}$ among Escherichia coli isolated from bovine mastitis in Ningxia, China. Foodborne Pathog Dis 2015;12:770-777. 